\title{
HOLISTIC APPROACH OF TEACHING OF GROSS PATHOLOGICAL SPECIMEN FOR 2ND PROFESSIONAL MBBS STUDENTS
}

\author{
Anupam Saha ${ }^{1}$
}

1 Professor, Department of Pathology, MGM Medical College, Kishanganj, Bihar.

ABSTRACT
BACKGROUND
Study of pathological specimen is necessary for the students towards their practical (including viva) as well as theoretical
examinations. Past experiences show that most of the students of 2nd Professional MBBS cannot answer properly the questions
related to the pathological specimen, especially the histopathological portion when asked by the examiners. This is due to the
conventional method of teaching where students are given only didactic lectures on histopathological features, which is not
convenient for students to understand the histopathology and related questions.

AIMS

To assess the impact of new teaching method of gross pathological specimen using visual aids (PowerPoint) to show histopathology.

\section{MATERIALS AND METHODS}

Total 41 students present in 2nd Prof. MBBS were divided into 4 groups under the leadership of class assistants or demonstrators. 20 practical classes were arranged for 4 months of study period. In the first one hour, each group was shown power-point presentation of histopathological features, related questions and answers of the gross specimen to be studied. All the aspects were discussed simultaneously. In the next one hour, there was a joint teaching session consisting of all four groups, moderated by the concerned professor with PowerPoint projection. Assessment was done by three mock tests comprising of Viva, Multiple Choice Questions and Short Assay type Questions and a routine internal assessment in the last week of the study period. Then a comparison was made with regards to presence of students and results of successive three mock tests. Result of internal assessment was compared with that of previous two batches in which students were taught with only routine lectures on the same gross pathological specimen.

\section{RESULTS}

The use of new method increased the average attendance of students significantly. The percentage of passing students in the mock tests was very good. There was notable increase of passing percentage in routine internal assessment in comparison to those of previous two years. Reflection of teaching is very encouraging as seen by increase in attendance, active and successful participation of students in group discussion followed by joint session.

\section{CONCLUSION}

This method increased interest by removing phobia regarding histopathology, which was reflected by significant increase of attendance of students in practical classes as well as better performance in mock tests and in a regular internal assessment in comparison to two previous years. From this feedback it is evident that the quality of teaching is also improved by this method. It has also served the purpose of our training regarding medical education technology in relation to group discussion, e-learning and intra-subject integrated teaching.

\section{KEYWORDS}

Gross Pathological Specimen, 2nd Professional MBBS, Histopathological Features.

HOW TO CITE THIS ARTICLE: Saha A. Holistic approach of teaching of gross pathological specimen for 2nd professional MBBS students. J. Evolution Med. Dent. Sci. 2016;5(47):2959-2963, DOI: 10.14260/jemds/2016/690

\section{INTRODUCTION}

Anatomical Pathology specimens-include tissues, blocks and slides derived from surgical procedures, autopsies and cytopathology testing. ${ }^{1}$

Financial or Other, Competing Interest: None.

Submission 23-04-2016, Peer Review 19-05-2016,

Acceptance 26-05-2016, Published 10-06-2016.

Corresponding Author:

Dr. Anupam Saha,

Professor,

Department of Pathology,

MGM Medical College,

Kishanganj-855107, Bihar

E-mail: dranupamsaha@yahoo.co.in

DOI: $10.14260 /$ jemds/2016/690
Study of pathological specimen is necessary for the students towards their practical (including viva) as well as theoretical examinations. Past experiences show that a significant portion of students of most of the medical colleges cannot answer properly the questions related to the pathological specimen when asked by the external as well as internal examiners.

With this project I would like to introduce another method, which is not complicated and can be used to increase the interest and participation of the student resulting in better learning.

So there is no doubt that the student become responsible for work-up and final sign-out of their cases and in other respects participate fully in the life of the department. ${ }^{2}$ 


\section{AIMS AND OBJECTIVES \\ AIMS}

- To assess the impact of new teaching method of gross pathological specimen, wherein visual aids (PowerPoint) to show histopathology were used along with the added mock tests.

- To introduce a holistic approach to teaching of gross pathological specimens along with their histopathological features.

\section{Specific Objectives}

- To overcome lack of interest and phobia regarding histopathological features and related study from the mind of students of 2nd professional MBBS.

- To effectively use the methods of group discussion, elearning and intra-subject integrated teaching for the better understanding for the students of 2 nd professional MBBS.

\section{MATERIALS AND METHODS}

Total 41 students present in 2nd MBBS were divided into 4 batches of 10 each under the leadership of class assistants or demonstrators. 20 practical classes were arranged in 4-month periods from $15^{\text {th }}$ October to $15^{\text {th }}$ February. Each class lasted for 60 minutes. During this one hour, each group was given a laptop consisting of power-point presentation of histological features, related questions and answers of the gross specimen to be studied. Total of 20 pathological specimens were studied. All the aspects were discussed simultaneously. In the next one hour, there was a joint teaching session consisting of all four groups moderated by the concerned professor with PowerPoint projection. The students participated with interest, because of better understanding of simultaneous histopathological corroboration. In contrast during earlier classes, students were given only dialectic lecture on histopathological features during the study of gross pathological specimen, which was not convenient for students of 2nd professional MBBS to understand the histopathology and related questions.

Assessment was done by mock Viva, Multiple Choice Questions (MCQ) and Short Assay Type Question (SAQ) for the specimens thus taught at the end of every month. After these three mock examinations, a routine internal assessment was taken after three and a half months on the pathological specimen in the same manner of previous years which included viva only.

Then a comparison was made with regards to presence of students and result of internal assessment for the students taught with new method and that of students of previous two years, who were taught with routine lectures on the same gross pathological specimen.

\section{OBSERVATIONS AND RESULTS}

The attendance rate of the students was much more as compared to those of earlier classes taught by conventional method. In the first two sessions, 23 and 26 students were present out of 41 respectively. After that it was increased steadily. The highest attendance was 39 . The average was 35.4 out of $41(86.3 \%)$. The percentages of attendance of students of same number of practical classes on pathological specimen during almost same period of the previous two years (2014 and 2015) were 56.6\% and 57.1\%. (Chart 1 and Table 1) From the conversation of students in group discussion it was found that they liked the method/approach very much. Almost all the students found it more interesting and answered the questions comfortably on microscopic features related to gross pathological specimen.

In the mock tests conducted, the performance was reasonably good in all the three successive mock tests. It was seen that the ability of recapitulation of complicated histopathological features related to gross specimen improved significantly. The percentages of passed students in this mock tests were $85.3 \%, 92.6 \%$ and $87.8 \%$. (Chart 2 and Table 2 ) In the last week of our study period, there was a regular internal assessment which was conducted in traditional method, i.e. without PowerPoint projection. However, the students scored well on the table of pathological specimen. The percentage of passing students was $82.93 \%$ and five students obtained above $90 \%$ marks. A comparison was made of this result with internal assessment of previous two years of the same period, where the percentages of passing students were $56.0 \%$ (2014) and 57.45\% (2015). (Chart 3 and Table 3) There was a significant increase in passing percentage by $25.48 \%$. The results and comparison were all related to the examination on gross pathological specimen only.

Comparison of average percentage of attendance of students in practical classes on gross pathological specimen ( $O$ n the basis of 20 classes in every year)

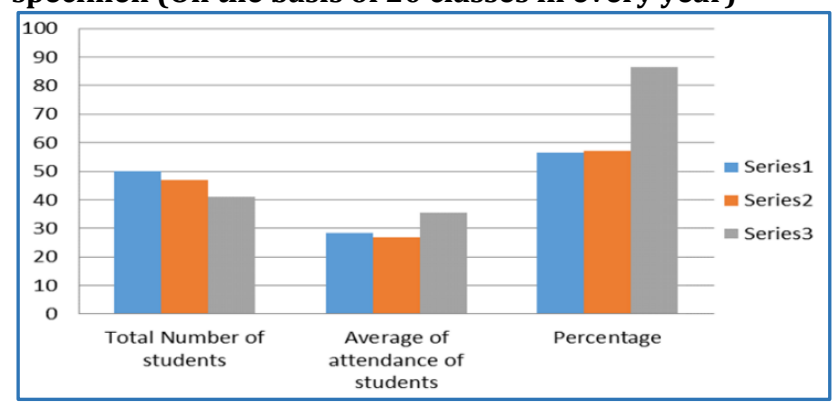

Chart 1

[Series 1: Year 2014, Series 2: Year 2015, Series 3: Year 2016]

\begin{tabular}{|c|c|c|c|}
\hline Year & $\begin{array}{c}\text { Total } \\
\text { Number of } \\
\text { Students }\end{array}$ & $\begin{array}{c}\text { Average of } \\
\text { Attendance of } \\
\text { Students }\end{array}$ & Percentage \\
\hline 2014 & 50 & 28.30 & $56.6 \%$ \\
\hline 2015 & 47 & 26.84 & $57.1 \%$ \\
\hline 2016 & 41 & 35.38 & $86.3 \%$ \\
\hline \multicolumn{3}{|c|}{ Table 1 } \\
\hline
\end{tabular}

Comparison of results of the students in mock tests of three consecutive months

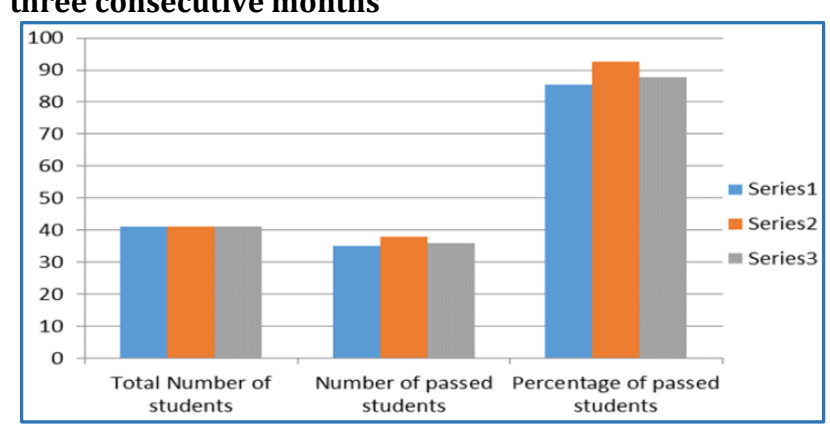

Chart 2

[Series 1: $1^{\text {st }}$ Month, Series 2: $2^{\text {nd }}$ Month, Series 3: $3^{\text {rd }}$ Month] 


\begin{tabular}{|c|c|c|c|}
\hline $\begin{array}{c}\text { Mock } \\
\text { Tests }\end{array}$ & $\begin{array}{c}\text { Total } \\
\text { Number of } \\
\text { Students }\end{array}$ & $\begin{array}{c}\text { Number of } \\
\text { Passed } \\
\text { Students }\end{array}$ & $\begin{array}{c}\text { Percentage of } \\
\text { Passed } \\
\text { Students }\end{array}$ \\
\hline $1^{\text {st }}$ Month & 41 & 35.00 & $85.3 \%$ \\
\hline $2^{\text {nd }}$ Month & 41 & 38.00 & $92.6 \%$ \\
\hline $3^{\text {rd }}$ Month & 41 & 36.00 & $87.8 \%$ \\
\hline \multicolumn{4}{|c|}{ Table 2} \\
\hline
\end{tabular}

Comparison of results of internal assessment on gross pathological specimen of consecutive three years: 2014, 2015 and 2016*

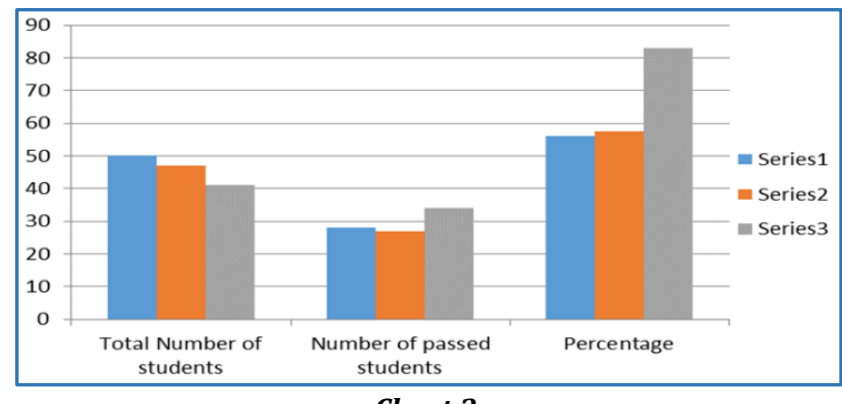

Chart 3

[Series 1: Year 2014, Series 2: Year 2015, Series 3: Year 2016]

\begin{tabular}{|c|c|c|c|}
\hline $\begin{array}{c}\text { Internal } \\
\text { Assessment } \\
\text { (Year) }\end{array}$ & $\begin{array}{c}\text { Total Number } \\
\text { of Students }\end{array}$ & $\begin{array}{c}\text { Number } \\
\text { of Passed } \\
\text { Students }\end{array}$ & $\%$ \\
\hline 2014 & 50 & 28.00 & $56.00 \%$ \\
\hline 2015 & 47 & 27.00 & $57.45 \%$ \\
\hline 2016 & 41 & 34.00 & $82.93 \%$ \\
\hline \multicolumn{3}{|c|}{ Table 3 } \\
\hline
\end{tabular}

* After the application of present method of teaching.

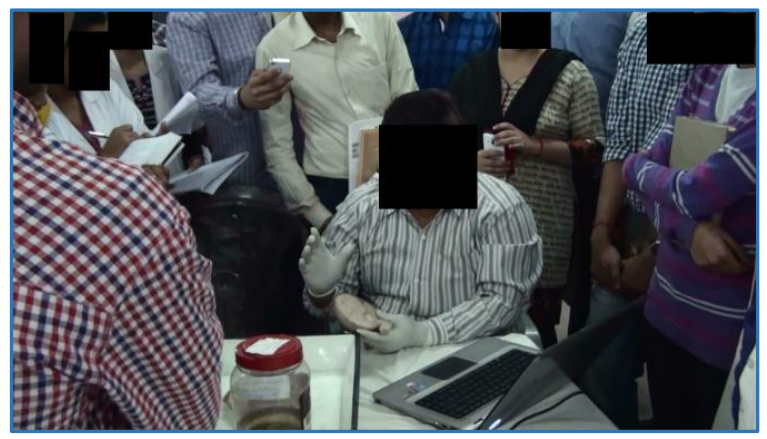

Picture 1: Photograph of Demonstration of Gross Pathological Specimen during Group Discussion

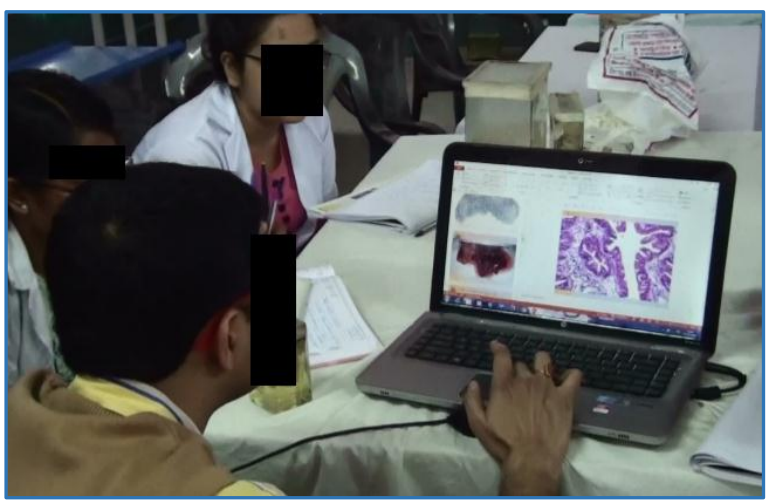

Picture 2: Photograph of Demonstration of Microscopic Features of Pathological Specimen during Group Discussion

\section{DISCUSSION}

Specially in peripheral medical colleges and even some other colleges, few of the most important specimens are not available for examination purpose. In most of the medical colleges, pathology specimens are shown to the students in large group, comprising of at least forty students without any histopathological corroboration by PowerPoint projection. This results in inadequate information being imbibed by the students. It is general consensus about better learning in small groups related to better understanding, critical and creative thinking, problem solving skills.3,4 and better student satisfaction. ${ }^{3,5,6,7}$ but not in terms of factual knowledge and assessment scores.3,8,9 The present study is based on small group discussion and e-learning. It is already established from several studies that small group discussion provides a unique environment to achieve high standard in medical education. 3,10 It is also evident that exchange of views, activation of prior knowledge, engagement at higher cognitive level are very much fruitful in deeper learning and better academic achievements by students.311,12 E-learning through digital pathology can be defined as the electronic capture, management, analysis and distribution of gross or microscopic specimens..$^{13}$ In the present study, simultaneous corroboration of histopathological features was done by PowerPoint projection, one of the powerful and popular tools of e-learning.

Microscopic pictures are taught at different times when the partial knowledge regarding the pathological specimen becomes almost volatile to the students. A continuous internal quality assurance study of the activities of an Anatomical Pathology Department in an Australian Teaching Hospital has been undertaken over a five-year period. ${ }^{14}$ But the same has not been endeavoured in our country. To a student of $2^{\text {nd }}$ professional MBBS, it is not at all easy to acquire adequate knowledge of histopathology on the study of gross specimen. To make it easy, the methodology executed in our study can be very useful. Furthermore, it is a combination of traditional teaching, small group discussion and e-learning method in practical classes. From our teaching experience, it is seen that even good students are less interested in pathology because of so called complex histopathological study basically appearing to them as a non-interesting entity. If we adopt this method/approach of teaching of pathological specimen we can easily remove the lack of interest and phobia regarding histopathology from the mind of $2^{\text {nd }}$ professional MBBS students. It will help the medical education system and ultimately we will get good pathologist as well as good clinician in future.

This study highlights that the use of simultaneous elearning method along with the traditional method of teaching of pathological specimen can help the students in a very scientific and fruitful approach for grasping histopathological as well as gross features of pathology specimen.

\section{OUTCOMES}

What this study adds? -Better learning of gross pathological specimen for the students of $2^{\text {nd }}$ professional MBBS through Group Discussion, e-learning and intra-subject integrated teaching.

\section{LIMITATIONS}

It is slightly difficult to use the electronic tools (e.g. laptop, etc.) to show histopathology related questions during the 
assessment and $2^{\text {nd }}$ professional final examination, because it will be time consuming to some extent. But in the interest of larger group of students, the problem can be solved by adding a few more minutes to total time allotted for the examination of gross pathological specimen. Furthermore, the sample size of this study is relatively less.

\section{REFLECTIONS}

\section{What was Good?}

Students showed interest in practical classes on gross pathological specimen, which was reflected by the increase in percentage of attendance in practical classes. Students scored good marks in mock tests as well as in regular internal assessment.

\section{What could have been differently?}

The result of $2^{\text {nd }}$ professional final MBBS Examination should be included in this study. That was not possible due to lack of time. The $2^{\text {nd }}$ professional final MBBS Examinations is yet to be completed.

\section{The Road Ahead}

This method of teaching on gross pathological specimen can be introduced on regular basis in our institute which will be followed by other departments like anatomy, microbiology, physiology, etc. of our institute and pathology and other departments of many other medical colleges of our country where it is applicable.

\section{CONCLUSIONS}

\section{Summary of Results}

1. With the new method, average percentage of attendance of students was significantly increased.

2. Students showed greater interest to the present method of teaching comprising of simultaneous gross description and exhibition of histopathological features by PowerPoint projection.

3. Students took part actively and successfully in group discussion followed by joint session.

4. Reflection of teaching is very encouraging, because the results of three consecutive mock tests were very good. And the percentage of the passed students in the regular internal assessment raised significantly in comparison to two previous years.

5. Quality of teaching was also found to be improved evident from student feedback.

\section{STUDY CONCLUSION}

From the present project it appears that, the approach of teaching of pathological specimen by this combined manner i.e. gross description, immediately followed by showing of histopathological feature and related questions and answers through electronic tools (e.g. PowerPoint projection by laptop) can be fruitful. It can remove the phobia regarding so called complicated histopathological features from the mind of $2^{\text {nd }}$ professional MBBS students to a great extent.

It was observed beyond reasonable doubt that students were recollecting the histopathological features and allied studies more effectively through this method of teaching, which got reflected in their assessments.
From the feedback of students during question answer session, group discussion, joint session, it can also be inferred that the quality of the teaching also got improved.

\section{Opinion}

It is very easy to adopt the above mentioned method if we are really enthusiastic and more careful to teach the students pathological specimen properly. If we introduce this teaching method in our pathology department on regular basis and if found fruitful in coming years, it can be followed in the other departments like anatomy, microbiology, physiology, etc. where it is applicable. In this way it will improve the quality of the teaching of our institute. Furthermore, this method can be conveyed to other medical colleges to adopt through seminars or workshops. So ultimately it will advance the status of the medical education of the nation.

\section{ACKNOWLEDGEMENT}

- $\quad$ All the mentors, MCI Nodal Centre, PSMC, Karamsad.

- All the reviewers, moderators, group leaders and group members (FIME batch, March 2015 and September 2015)

- All the colleagues of Department of Pathology, MGM Medical College, Kishanganj, Bihar.

- $\quad$ All the students of 2nd Professional MBBS (2016), MGM Medical College, Kishanganj, Bihar.

\section{REFERENCES}

1. Whiley M. Use of Anatomical Pathology Specimens for Research. Clinical and Statewide services. (Approver/s) Document Number: 24719V3, 2009;1-6.

2. Crain. Medical Student elective course descriptions. John Hopkins, School of medicine, Department of pathology 2015;1.

3. Hameed S, Khalid T, Aslam S, et al. Small group discussionimpact on student's test scores in an undergraduate pathology course. Journal of University Medical \& Dental College 2013;4(1):17-21.

4. de Jong Z, van Nies JA, Peters SW, et al. Interactive seminars or small group tutorials in preclinical medical education: results of a randomized controlled trial. Bio Med Central Medical Education 2010;10:79.

5. Kitchen M. Facilitating small groups: how to encourage student learning. Clin Teach 2012;9(1):3-8.

6. Schmidt HG, Rotgans JI, Yew EH. The process of problembased learning: what works and why. Medical education 2011;45(8):792-806

7. Pal R, Kar S, Zaman FK, et al. Assessment of impact of small group teaching among students in community medicine. Indian Journal of Community Medicine 2012;37(3):17073.

8. Khan I FA. Problem-Based Learning Variant: transition phase for a large institution. Journal of Pakistan Medical Association 2001;51:271.

9. Tayyeb R. Effectiveness of Problem based learning as an instructional tool for acquisition of content knowledge and promotion of critical thinking among medical students. Journal of the College of Physicians and Surgeons Pakistan 2013;23(1):42-6. 
10. Nandi PL, Chan JNF, Chan CPK, et al. Undergraduate medical education: comparison of problem-based learning and conventional teaching. Hong Kong Medical Journal 2000;6(3):301-6.

11. Jones RW. Teaching and learning in small groups: characteristics, benefits, problems and approaches. Anaesthesia and intensive care 2007;35:587-92.

12. Steinert Y. Student perceptions of effective small group teaching. Medical Education 2004;38(3):286-93.
13. Brian K Chiu, Kim Solez, Consolato M Sergi. Digital pathology for E-learning and digital education-a review. Journal of Information Technology and Application in Education 2014;3(4):164-168.

14. Zardawi IM, Bennett G, Jain S, et al. Internal quality assurance activities of a surgical pathology department in an Australian teaching hospital. Journal of Clinical Pathology 1998;51(9):695-699. 